\title{
A novel index for predicting intraocular pressure reduction following cataract surgery
}

\author{
S A Issa, J Pacheco, U Mahmood, J Nolan, S Beatty
}

Br J Ophthalmol 2005;89:543-546. doi: 10.1136/bjo.2004.047662

Aim: The results of a study designed to investigate the predictive value of preoperative anterior chamber depth (ACD) and intraocular pressure (IOP) are reported. The relation between these factors and their effect on the reduction in IOP following phacoemulsification cataract surgery was also studied.

Methods: The ACD and IOP were prospectively measured in 103 non-glaucomatous eyes of 103 patients who underwent uneventful phacoemulsification and posterior chamber intraocular lens (PCIOL) implantation. Other data which were recorded included best corrected visual acuity, axial length, lens thickness, and severity of lens opacity.

Results: The ACD increased by a mean (SD) of 1.10 (0.44) $\mathrm{mm}(\mathrm{p}<0.00001)$ and this increase was significantly and inversely related to preoperative $A C D\left(r^{2}=68 \% ; p<0.01\right)$. IOP dropped by a mean of $2.55(1.78) \mathrm{mm} \mathrm{Hg}$ following cataract surgery $(p<0.0001)$, and this reduction was significantly and positively related to preoperative IOP $\left(r^{2}=56 \% ; p<0.01\right)$, and significantly and inversely related to preoperative $\operatorname{ACD}\left(r^{2}=21 \% ; p<0.01\right)$. A novel ratio, the pressure to depth (PD) ratio (preoperative IOP/preoperative $A(D)$, was found to be significantly and positively related to the surgically induced reduction in IOP $\left(r^{2}=73 \% ; p<0.01\right)$, and IOP was reduced by $\geqslant 4 \mathrm{~mm} \mathrm{Hg}$ in all patients with a PD ratio $>7$.

Conclusion: The reduction in IOP following cataract surgery was found to be positively related to preoperative IOP, and inversely related to preoperative ACD. Furthermore, these results indicate that a novel index, the PD ratio, is strongly predictive for IOP reduction following cataract extraction, and may prove useful in surgical decision making.

A $\mathrm{n}$ increase in anterior chamber depth (ACD) has been reported after cataract extraction, ${ }^{1-5}$ and a significant drop in intraocular pressure (IOP) following this surgery has also been well documented, ${ }^{6-8}$ especially in eyes with narrow angles where it has been found that cataract extraction can permanently normalise IOP. ${ }^{9-14}$

However, the relation between preoperative parameters and IOP reduction after cataract extraction has not been well described. In this study, we investigated whether preoperative ACD and IOP, and the relation between these variables, are predictive for the surgically induced changes in IOP following phacoemulsification in cataractous eyes.

\section{METHODS}

We prospectively studied 103 eyes of 103 patients without ocular co-morbidity, all of whom underwent phacoemulsification between October 2002 and December 2003. All subjects were assessed by the same clinician (SI), who was masked to patients' identity; however, it was not possible to mask pseudophakia. This study was approved by the ethics committee of Waterford Regional Hospital and eyes with a history of trauma or surgery were excluded.

The following were recorded in the preoperative assessment, which is typically $1-2$ weeks before surgery: best corrected visual acuity (BCVA); ACD; lens thickness; axial length (AXL); IOP; and severity of lens opacity. The same details, except lens thickness and grade of lens opacity, were recorded $8-9$ weeks after surgery, and 4 weeks after discontinuation of topical steroids.

The BCVA was measured using a Snellen chart at 6 metres, and was converted into logMAR equivalent (counting fingers, hand movements, and perception of light were given arbitrary values of 1.7, 1.8, and 1.9, respectively). ${ }^{15}$

The ACD, lens thickness, and AXL were measured using an ultrasound A-scanner (Sonomed Model 100A) by the contact technique. ${ }^{16}$ This method of has been validated by previous investigators ${ }^{17}{ }^{18}$ and three readings were taken and averaged.

Three readings of IOP were measured using a Goldmann applanation tonometer attached to a slit lamp, and the mean was recorded. All IOP measurements were taken between $11 \mathrm{am}$ and $4 \mathrm{pm}$. The cataract was classified according to the Lens Opacities Classification System (LOCS-III). ${ }^{19}$

Surgical procedures were performed under retrobulbar anaesthesia: Xylocaine-MPF 4\%, Hyalase, and Chirocaine. All operations were performed through a $2.85 \mathrm{~mm}$ clear corneal incision. A continuous curvilinear capsulorrhexis was completed following viscoelastic injection and hydrodissection was performed using BSS. After removal of the nucleus and cortex, a foldable, posterior chamber intraocular lens (PCIOL) was implanted in the capsular bag following enlargement of the incision to 3.2-3.5 mm. PCIOLs included Acrysof MA30BA or an Akreos Adapt lens. A 10/0 Nylon thread was used to seal the corneal incision if corneal stromal hydration was insufficient. Subconjunctival injection of $0.25 \mathrm{ml}$ of DBL (dexamethasone) and $0.7 \mathrm{ml}$ of Zinacef was given.

Data were analysed by SPSS software package (version 11) and differences between preoperative and postoperative values were assessed by the paired Student two tailed $t$ test. Categorical data were analysed using the $\chi^{2}$ test, and correlations between continuous data were assessed using the Pearson correlation coefficient. Multiple linear regression was performed in order to investigate the relation between IOP drop and several variables. A p value of less than 0.05 was considered statistically significant.

\section{RESULTS}

We studied 103 eyes (57 left and 46 right eyes) of 103 volunteers. Mean age (SD) was 76.07 (9.33) years (table 1),

Abbreviations: $A C D$, anterior chamber depth; $A C G$, angle closure glaucoma; AXL, axial length; BCVA, best corrected visual acuity; IOP, intraocular pressure; PCIOL, posterior chamber intraocular lens; PD ratio, pressure to depth ratio 


\begin{tabular}{|c|c|c|c|}
\hline & Before surgery & After surgery & $\begin{array}{l}\text { Paired } t \text { test } \\
\text { ( } p \text { value) }\end{array}$ \\
\hline $\begin{array}{l}\text { Age (years) } \\
\text { range }\end{array}$ & $\begin{array}{l}76.07(9.33) \\
43-94\end{array}$ & & \\
\hline $\begin{array}{l}\text { BCVA (logMAR) } \\
\text { range }\end{array}$ & $\begin{array}{l}0.6(0.53) \\
0.1-1.9\end{array}$ & $\begin{array}{l}0.2(0.2) \\
0.0-1.0\end{array}$ & $<0.00001$ \\
\hline $\begin{array}{l}\mathrm{ACD}(\mathrm{mm}) \\
\text { range }\end{array}$ & $\begin{array}{l}2.97(0.44) \\
1.88-4.82\end{array}$ & $\begin{array}{l}4.07(0.34) \\
3.11-5.14\end{array}$ & $<0.00001$ \\
\hline $\begin{array}{l}\mathrm{IOP}(\mathrm{mm} \mathrm{Hg}) \\
\text { range }\end{array}$ & $\begin{array}{l}15.23(2.47) \\
6-23\end{array}$ & $\begin{array}{l}12.68(1.65) \\
6-15\end{array}$ & $<0.00001$ \\
\hline $\begin{array}{l}\text { Lens thickness }(\mathrm{mm}) \\
\text { range }\end{array}$ & $\begin{array}{l}4.30(0.59) \\
2.2-5.55\end{array}$ & & \\
\hline $\mathrm{AXL}(\mathrm{mm})$ & $23.10(0.97)$ & $23.14(0.98)$ & 0.1444 \\
\hline range & $20.57-25.72$ & $20.44-25.78$ & \\
\hline
\end{tabular}

and $43.7 \%$ were male and $56.3 \%$ were female. BCVA was found to improve significantly from $0.6(0.53)$ to $0.2(0.2)$ $(\mathrm{p}<0.00001)$.

Mean preoperative and postoperative ACD were 2.97 (0.44) $\mathrm{mm}$ and $4.07(0.34) \mathrm{mm}$, respectively, and this represented a mean increase of $1.10(0.44) \mathrm{mm}(\mathrm{p}<0.00001)$ (fig l). There was a statistically demonstrable inverse relation between preoperative ACD and the extent of ACD increase $\left(r=-0.8215, r^{2}=68 \% ; \mathrm{p}<0.01\right)$.

Mean lens thickness was $4.30(0.59) \mathrm{mm}$ and was positively related to the increase in ACD $(r=0.306$; $\mathrm{p}=0.002)$, but was not significantly related to changes in IOP $(p=0.579)$. It was also noted that lens thickness was inversely related to preoperative $\operatorname{ACD}(r=-0.332 ; \mathrm{p}=0.001)$.

The mean grade of lens opacification was 4.2 (1.1) for nuclear opalescence; 4.2 (1.1) for nuclear colour; 2.4 (1.5) for cortical lens opacity; and 1.8 (1.9) for posterior subcapsular opacities, and none of these were significantly related to changes in IOP (range of p: 0.069-0.916) or ACD (range of p: $0.073-0.217)$.

Of note, no statistically significant difference in terms of changes in ACD or IOP could be attributed to PCIOL type (ACD: $p=0.572$; IOP: $p=0.665$ ) and there was no statistically significant difference between preoperative and postoperative AXL $(\mathrm{p}=0.1444)$.

Mean preoperative and postoperative IOP were 15.23 (2.47) $\mathrm{mm} \mathrm{Hg}$ and 12.68 (1.65) $\mathrm{mm} \mathrm{Hg}$ respectively, and this represents a mean drop of 2.55 (1.78) $\mathrm{mm} \mathrm{Hg}(\mathrm{p}<0.0001)$. The extent of IOP reduction postoperatively was directly related to preoperative IOP $\left(r=0.745 ; r^{2}=56 \% ; \mathrm{p}<0.01\right)$ (fig 2). Furthermore, it was noted that IOP reduction was inversely related to preoperative ACD $\left(r=-0.455 ; r^{2}=21 \%\right.$; $\mathrm{p}<0.01$ ) (fig 3 ). Other variables including age, sex, lens thickness and preoperative AXL were not significantly related

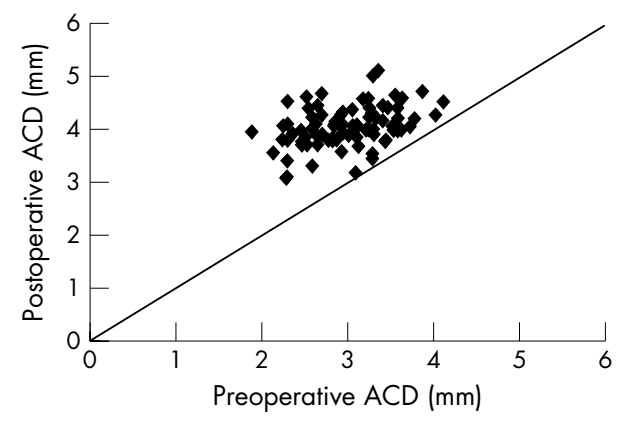

Figure 1 The relation between preoperative and postoperative ACD after cataract surgery. The solid line plotted is the line of equivalence.

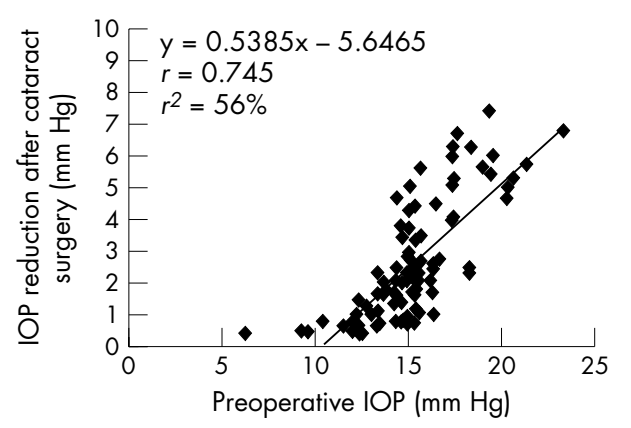

Figure 2 The relation between preoperative IOP and IOP reduction after cataract surgery. Note that IOP drop is plotted as a positive value. Random noise of not more than plus or minus 0.1 was superimposed onto both $x$ and $y$ values to ensure that a maximum number of data points were visually represented. IOP, intraocular pressure.

to IOP reduction (multivariate analysis) (range of $\mathrm{p}$ values: $0.174-0.869$ ).

We investigated the predictive value of a novel ratio (preoperative IOP/preoperative ACD), and named this the pressure to depth ratio, or $\mathrm{PD}$ ratio. The $\mathrm{PD}$ ratio was positively related to the extent of IOP reduction $(r=0.852$; $r^{2}=73 \% ; \mathrm{p}<0.01$ ) (fig 4 ). Twenty nine eyes $(28 \%)$ had a PD ratio $>6.0$, and they exhibited a mean reduction in IOP of 4.90 (1.34) $\mathrm{mm} \mathrm{Hg}$, and this reduction was significantly greater than for eyes with a $\mathrm{PD}$ ratio $<6.0$ who had a mean IOP reduction of $1.64(0.84) \mathrm{mm} \mathrm{Hg}(\mathrm{p}<0.001)$. Furthermore, $96 \%$ of eyes with a PD ratio $>6.0$ exhibited an IOP drop of $\geqslant 2 \mathrm{mmHg}$, compared with only $38 \%$ of those with a PD

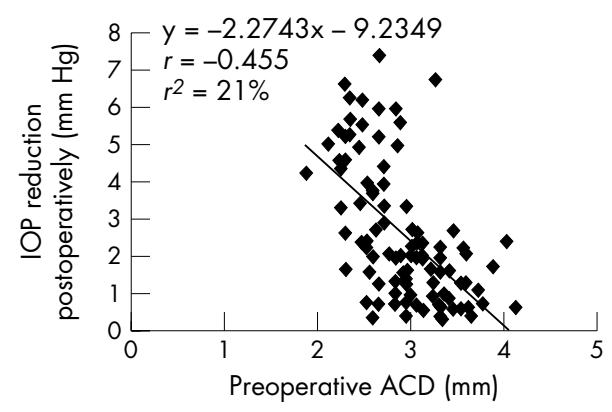

Figure 3 The relation between preoperative $A C D$ and IOP reduction following cataract surgery. Note that IOP drop is plotted as a positive value. Random noise of not more than plus or minus 0.1 was superimposed onto IOP drop values to ensure that a maximum number of data points were visually represented. $A C D$, anterior chamber depth; $\mathrm{IOP}$, intraocular pressure. 


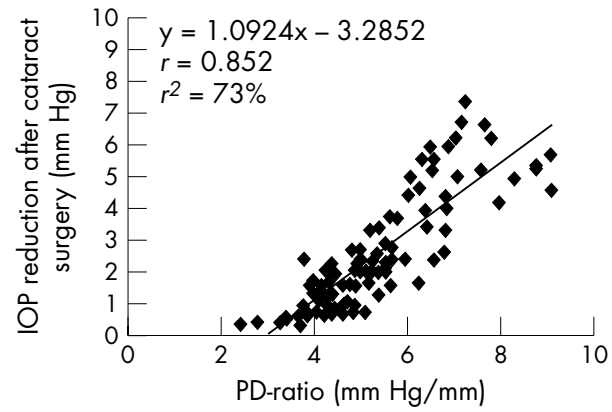

Figure 4 The relation between PD ratio and IOP reduction following cataract surgery. Note that IOP drop is plotted as a positive value. Random noise of not more than plus or minus 0.1 was superimposed onto IOP drop values to ensure that a maximum number of data points were visually represented. IOP, intraocular pressure; PD ratio, intraocular pressure to anterior chamber depth ratio.

ratio $<6.0(\mathrm{p}<0.001)$. Indeed, all eyes with a $\mathrm{PD}$ ratio $>7.0$ exhibited an IOP reduction of at least $4 \mathrm{~mm} \mathrm{Hg}$ (fig 4).

\section{DISCUSSION}

We have shown that ACD increased significantly by a mean of $1.10 \mathrm{~mm} 8$ weeks postoperatively, which is comparable to reports of Hayashi et al. ${ }^{13}$ They also found that, after surgery, the ACD in eyes with angle closure glaucoma (ACG) became almost identical to those in the non-glaucomatous eyes, indicating that cataract extraction may negate the anatomical predisposition to ACG. ${ }^{13}$ Indeed, Gunning and Greve advocated cataract extraction for ACG as they found that it resulted in IOP reduction to the same extent as did filtering surgery, with fewer complications. ${ }^{12}$

Several studies have demonstrated that cataract extraction and IOL implantation lowers IOP to some extent in eyes with primary open angle glaucoma (POAG) ${ }^{13} 20$ and non-glaucomatous eyes, ${ }^{13}{ }^{21}$ and that this IOP reduction lasts for at least 12 months after phacoemulsification surgery in non-glaucomatous eyes. ${ }^{13} 22$ However, previous workers have not investigated preoperative parameters which may be of predictive value for IOP reduction following cataract surgery.

We have demonstrated a significant IOP reduction, by a mean of $2.55 \mathrm{~mm} \mathrm{Hg}, 8-9$ weeks after cataract surgery in non-glaucomatous eyes, which is comparable to a study by Tong et al. ${ }^{21}$ This reduction in IOP was more marked in patients with a higher preoperative IOP, and we also showed that this reduction was inversely related to preoperative ACD. The observation that lens thickness was positively and negatively related to increases in ACD and preoperative $A C D$, respectively, suggests that any relation that might exist between lens thickness and IOP reduction following cataract surgery is likely to be mediated through its relation with ACD. In our study comprising 103 eyes, no significant relation between lens thickness and surgically induced IOP reduction was observed.

A novel ratio, incorporating preoperative ACD and IOP, was found to be more strongly predictive for IOP reduction following cataract surgery $\left(r^{2}=73 \%\right)$ than either of these parameters in isolation $\left(r^{2}=21 \%\right.$ for ACD and $56 \%$ for IOP). Thus, the PD ratio may be a useful tool in the management of non-glaucomatous eyes where a high IOP reduction is desirable and where cataract exists.

Tong et al have shown that IOP reduction was statistically similar for non-glaucomatous and glaucomatous eyes 6 months after phacoemulsification and PCIOL implantation. ${ }^{21}$ Others have found that the reduction in IOP after cataract extraction can allow for reduced use of postoperative antiglaucoma medication in POAG patients. ${ }^{23}$ Should the predictive value of the PD ratio be confirmed in further study on eyes with POAG, it may be reasonable to incorporate its use into the surgical decision making process in an attempt to avoid the greater risk of complications inherent in glaucoma filtration surgery when compared with cataract surgery. ${ }^{24} 25$

Mechanisms that have been hypothesised to explain the reduction in IOP following cataract surgery include: improvement of aqueous outflow facility by widening the drainage angle ${ }^{13} 26$; and/or an effect on the ciliary body (by capsular bag contraction) which results in reduced aqueous production. ${ }^{21}$ Although the mechanism of IOP reduction following cataract surgery remains uncertain, our results indicate that it is a function of both preoperative ACD and IOP.

The major limitation of our study resides in its short follow up period. However, previous investigators have shown that the IOP lowering effect of phacoemulsification persists for at least 12 months. ${ }^{21}$ Also, we did not measure corneal thickness which could influence IOP measurements, as increased corneal thickness has been associated with falsely high IOP readings in previous studies. ${ }^{27-29}$

In conclusion, we describe a ratio that incorporates preoperative ocular parameters, which can be easily measured in a clinical setting, and appears to be strongly predictive for IOP reduction following cataract surgery in non-glaucomatous eyes. Eyes with a higher PD ratio exhibited a greater reduction in IOP. Further study, with longer follow up, is needed to investigate the potential role of the PD ratio in non-glaucomatous and glaucomatous eyes if its value in surgical decision making is to be confirmed or refuted.

\section{Authors' affiliations}

S A Issa, J Pacheco, U Mahmood, J Nolan, S Beatty, Department of Ophthalmology, Waterford Regional Hospital, Waterford, Republic of Ireland

Correspondence to: Dr Sharif A Issa, Department of Ophthalmology, Waterford Regional Hospital, Waterford, Republic of Ireland; sharifissa@yahoo.co.uk

Accepted for publication 1 October 2004

\section{REFERENCES}

1 Troutman RC, Goldman JN, Binkhorst RD, et al. Anterior chamber depth in aphakia. Trans Am Ophthalmol Soc 1963;61:385.

2 Landegger GP, Roth N. Anterior chamber depth and its stability in aphakia. Am J Ophthalmol 1968;65:706-8.

3 Norn MS. Depth of anterior chamber after cataract extraction. Br J Ophthalmol 1978;62:474-7.

4 Arai $M$, Ohzuno I, Zako M. Anterior chamber depth after posterior chamber intraocular lens implantation. Acta Ophthalmol 1994:72:694-7.

5 Kurimoto $Y$, Park M, Sakave $H$, et al. Changes in the anterior chamber configuration after small-incision cataract surgery with posterior chamber intraocular lens implantation. Am J Ophthalmol 1997; 124:775-80.

6 McGuigan LJB, Gottsch J, Stark WJ, et al. Extracapsular cataract extraction and posterior chamber lens implantation in eyes with preexisting glaucoma. Arch Ophthalmol 1986; 104:1301-8.

7 Steuhl KP, Marahrens P, Frohn C, et al. Intraocular pressure and anterior chamber depth before and after extracapsular cataract extraction with posterior chamber lens implantation. Ophthalmic Surg 1992;23:233-7.

8 Cekic O, Batman C, Totan Y, et al. Changes in anterior chamber depth and intraocular pressure after phacoemulsification and posterior chamber intraocular lens implantation. Ophthalmic Surg Lasers 1998;29:639-42.

9 Acton J, Salmon JF, Scholtz R. Extracapsular cataract extraction with posterior chamber lens implantation in primary angle-closure glaucoma. J Cataract Refract Surg 1997;23:930-4

10 Wishart PK, Atkinson PL. Extracapsular cataract extraction and posterior chamber lens implantation in patients with primary chronic angle-closure glaucoma: effect on intraocular pressure control. Eye 1989;3:706-12.

11 Gunning FP, Greve EL. Uncontrolled primary angle closure glaucoma: results of early intercapsular cataract extraction and posterior chamber lens implantation. Int Ophthalmol 1991;15:237-47.

12 Gunning FP, Greve EL. Lens extraction for uncontrolled angle-closure glaucoma: long-term follow-up. J Cataract Refract Surg 1998;24:1347-56.

13 Hayashi K, Hayashi $\mathrm{H}$, Nakao F, et al. Changes in anterior chamber angle width and depth after intraocular lens implantation in eyes with glaucoma. Ophthalmology 2000;107:698-703. 
14 Greve EL. Primary angle closure glaucoma: extracapsular cataract extraction or filtering procedure? Int Ophthalmol 1988;12:157-62.

15 Holladay JT. Proper method for calculating average visual acuity. J Refract Surg 1997;13:388-91.

16 Hennessy MP, Chan DG. Contact versus immersion biometry of axial length before cataract surgery. J Cataract Refract Surg 2003;29:2195-8.

17 Koranyi G, Lydahl E, Norrby S, et al. Anterior chamber depth measurement A-scan versus optical methods. J Cataract Refract Surg 2002;28:243-247.

18 Tehrani M, Krummenauer F, Blom E, et al. Evaluation of the practicality of optical biometry and applantation ultrasound in 253 eyes. J Cataract Refract Surg 2003;29:741-6.

19 Chylack LT, Wolfe JK, Singer DM, et al. The lens opacities classification system III. Arch Ophthalmol 1993;111:831-6.

20 McMahan LB, Monica ML, Zimmerman TJ. Posterior chamber pseudophakes in glaucoma patients. Ophthalmic Surg 1986;17:146-50.

21 Tong JT, Miller KM. Intraocular pressure change after sutureless phacoemulsification and foldable posterior chamber lens implantation. $J$ Cataract Refract Surg 1998;24:256-62.

22 Tennen DG, Masket S. Short- and long-term effect of clear corneal incisions on intraocular pressure. J Cataract Refract Surg 1996;22:568-70.
23 Kim DD, Doyle JW, Smith MF. Intraocular pressure reduction following phacoemulsification cataract extraction with posterior chamber lens implantation in glaucoma patients. Ophthalmic Surg Lasers 1999;30:37-40.

24 Beck AD. Advanced Glaucoma Intervention Study. Review of recent publications of the Advanced Glaucoma Intervention Study. Curr Opin Ophthalmol 2003;14:83-5.

25 Jacobi PC, Dietlein TS, Krieglstein GK. The risk profile of trabecular aspiration versus trabeculectomy in glaucoma triple procedure. Graefes Arch Clin Exp Ophthalmol 2000;238:545-51.

26 Meyer MA, Savitt ML, Kopitas E. The effect of phacoemulsification on aqueous outflow facility. Ophthalmology 1997; 104:1221-7.

27 Gordon MO, Beiser JA, Brandt JD, et al. The Ocular Hypertension Treatment Study: baseline factors that predict the onset of primary open-angle glaucoma. Arch Ophthalmol 2002;120:714-20.

28 Shah S, Chatterjee A, Mathai M, et al. Relationship between corneal thickness and measured intraocular pressure in a general ophthalmology clinic. Ophthalmology 1999;106:2154-60.

29 Whitacre MM, Stein RA, Hassanein K. The effect of corneal thickness on applanation tonometry. Am J Ophthalmol 1993;115:592-6.

\section{Register now!}

10th European Forum on Quality Improvement in Health Care 13-15 April 2005, ExCel Conference Centre, London For further information on how to register please go to: http://www.quality.bmipg.com 